\title{
Gender in Futures: A Study of Gender and Feminist Papers Published in Futures, 1969-2009
}

\section{Introduction}

A gender perspective in research often involves examining historical and contemporary representations of women and men and applying critical gender analysis on culture, identity, politics, etc. In this paper the gender perspective is stretched into the future. Gender studies are closely linked to normative feminist research, striving for a world where men and women can function freely and fairly, which could be seen as a feminist future goal. However, this goal is often rather imprecise. Correspondingly, normative futures studies aim at reaching important targets, e.g. ecological sustainability. Although futures studies seldom have a gender perspective or feminist aim, attempts have been made to integrate a gender/feminist perspective into futures studies and some writers have done considerable works in this field.

This paper reviews and discusses papers related to women's studies, gender or feminist perspective, published in the scientific journal Futures. The aim is to provide new understandings and remapping of futures studies by capturing how gender is created and understood in this field.

The research approach is interpretative and qualitative, rooted in constructivist orientation. While the primary researchers were influenced by their specific context, in this meta-study I was influenced by today's context and conceptualisations in searching for meaning by discerning and reframing knowledge. This process extends from 'what is' to 'what might be' [1, p. 14]. It is also a way of consolidating a body of scattered literature into a coherent whole.

The theoretical framework chosen for this meta-study was feminist theory together with futures studies. While feminist theory is diverse, it rests on some common foundations: (a) women are subordinated men; (b) traditional ways of thinking support this subordination and neglect or trivialise issues particularly affecting women; and (c) this patriarchal order should be changed [2, pp. 5484-5485, 3, p. 13]. Thus, feminist theory has an inherent will to change and Haug [4, p. 53] even claims that 'the situation of women today is so muddled and patriarchy is so solid, so alive and well, that improvements in the here and now do not suffice'. However, these common starting 
points say little about what needs to be changed, the short- and long-term strategies needed and the actual goal, the feminist future.

Sometimes gender studies and feminist research are used synonymously and gender research would not exist were it not for the feminist momentum [5]. West and Zimmerman [6, p. 126] state that gender is a situated doing, i.e. both an outcome and a rationale for various social situations and arrangements. Gender research therefore means investigating how people think, interpret, perceive, symbolise, feel, describe and define sex/gender [5]. Similarly, in futures studies the future is not a disconnected endstate, but it is rooted in both the past and present [7, 8]. Thus, a social constructionist perspective is present in futures studies, although often only implicitly [9]. Futures studies contain many approaches and are made with different intentions [7, 10, 11], leading some writers to view it as too fragmented to be an academic field [see 7, p. 66 ff, for discussion]. One way of classifying the different approaches within futures studies is in response to the questions 'what will happen', 'what can happen' and 'how can a specific target be reached' [10]. Here, these are denoted probable, possible and preferable futures.

\section{Selection of papers}

The papers studied here are all published in Futures. This international, peer-reviewed, multidisciplinary journal was chosen as it covers methods and practices of futures studies. It is 'concerned with medium and long-term futures of cultures and societies, science and technology, economics and politics, environment and the planet and individuals and humanity' [12]. It 'seeks to examine possible and alternative futures of all human endeavours' [12]. Futures has citation impact factor of 1.014, placing it 18th among 43 journals in the 'planning and development' category [13]. None of the three top journals on this list (Research Policy, Journal of the American Planning Association and World Bank Economic Review) focuses on futures studies. Technological Forecasting and Social Change (ranked 4th) has a technological focus [14] but was not as relevant as Futures for this study because of its technological orientation. The futures studies journal Journal of Forecasting (ranked 34th) is multidisciplinary but calls particularly for 'papers dealing with modelling issues and the relationship of forecasting systems to decision-making processes' [15], so is not so relevant for this study.

Futures wants to 'stimulate the systematic use and growth of futures literature'. One of the criteria for publication 'is an indication of how the article relates to others in the futures literature' [16]. Thus, articles 'must show awareness of the futures field and make original contributions to advancement of knowledge in futures studies' [16].

Futures is primarily a journal about futures studies, not gender or feminist studies. However, a special issue called Women and the future (Volume 7, Issue 5) was published in 1975, followed by Gender and change (Volume 21, Issue 1) in 1989. The latest special issue on gender/feminist futures, Feminist futures (Volume 40, Issue 4) 
came in 2008. In 2006 a special issue was dedicated to Masini, who has done much work on women and change (Volume 38, Issue 10). Thus, there is an interest in bringing gender/feminist research into the field of futures studies. In addition to these special issues, papers with a gender/feminist perspective have been published now and then.

In order to find papers of interest, I searched all abstracts, titles and keywords of published papers on Futures online (until the end of 2009) for the words: gender, feminism, feminist, women/woman and sex (Table 1). Women/woman was used as a search word because gender/feminist studies are sometimes denoted women's studies, but also because women are often the focus of gender research [17]. Some hits referring to book reviews were excluded, and some occurred in several searches/special issues. In all, there were 98 unique hits, of which 20 were deemed non-relevant. 6 of these were conference reports and 14 used the search words to a very limited extent. Thus, 78 papers were analysed. This could be compared to 4456 papers published all in all, 19682009.

Table 1. Key words

\begin{tabular}{|l|l|}
\hline Keyword & $\begin{array}{l}\text { Number of } \\
\text { relevant hits }\end{array}$ \\
\hline Gender & 19 \\
\hline Feminism & 5 \\
\hline Feminist & 10 \\
\hline Women/woman & 54 \\
\hline Sex & 9 \\
\hline Special Issue & \\
\hline Women \& future & 8 \\
\hline Gender \& change & 12 \\
\hline Masini & 6 \\
\hline Feminist futures & 7 \\
\hline Total & $\mathbf{1 3 0}$ \\
\hline Unique hits & $\mathbf{7 8}$ \\
\hline
\end{tabular}

\subsection{READING THE PAPERS}

The themes identified emerged on reading the selected papers. However, these were coloured by the theoretical frameworks chosen and the questions asked while reading the texts. In seeking a relationship between feminist studies and futures studies, I found general criticism of futures studies and therefore examined the papers looking for new/alternative methods for envisioning feminist futures. Another theme that arose was the view of women as drivers for change. Thus, the four themes chosen were: 1) criticisms of futures studies, 2) new methods, 3) women-friendly/feminist visions and 4) women as drivers for change. Table 2 shows the number of papers related to each 
theme. I studied 78 papers, but some papers proved relevant for more than one theme. The papers could have been classified in other ways and some papers could have been placed under different themes. However, the idea was not to classify the papers, but to give an interesting and relevant structure to the meta-study.

Research questions linked to the themes were:

1. What kind of criticism? Why?

2. What methods are suggested? Why? What problems do they want to solve?

3. How are feminist visions described? Why?

4. In what ways are women described as drivers for change? Why?

\section{Table 2. Themes}

\begin{tabular}{|l|l|l|}
\hline & Theme & Number of papers \\
\hline 1 & Criticism of futures studies & 18 \\
\hline 2 & New methods & 25 \\
\hline 3 & $\begin{array}{l}\text { Towards women-friendly } \\
\text { feminist visions }\end{array}$ & 36 \\
\hline 4 & Women as drivers for change & 25 \\
\hline
\end{tabular}

\section{Findings from the papers}

\subsection{THEME 1: CRITICISMS OF FUTURES STUDIES}

\subsubsection{Male-dominated}

A common thread in feminist criticisms of futures studies is that they are maledominated and male-biased [18, 19, 20, 21, 22, 23, 24, 25]. This means that '[m]en still get most of the exposure in media coverage of future, write most of the books about futures, hold most of the professional posts dealing with futures' but also that traditionally female issues like food are excluded [18, p. 699]. Milojevic [21, p. 330] sees three reasons for the exclusion of women:

- General exclusion of women from professional activity

- Hypertechnological and scientific orientation of mainstream futures studies

- Disproportionate focus on the fields of economics and international politics in futures studies and on the impact of new technologies 
Hicks [26] surveyed young people's view on the future and found that in the UK girls were more interested in the future and valued education more and material things less than boys. Girls were also less optimistic about the future than boys, who were readily seduced by 'the glamour of hi-tech solutions for everything' [26, p. 10]. Similarly, in their exploration of people's views on the future, Tepperman and Curtis [27, p. 552] found that boys in Austria, England and Finland expressed more concern about the material aspects of life, while girls expressed more hopes and worries about human relationships.

\subsubsection{The colonised future}

By dominating futures studies, Western males are colonising the future [22]. Sardar [22] and Milojevic [20] also stress that non-Western cultures are being marginalised from the future. Feminist theorising about the future is limited and although some futurists engage with gender, such efforts are 'sidelined as a 'special' (read: 'optional') issue within the field' [21, p. 330]. Kelly [28, p. 562] believes that futurist thinking is characterised by a lack of attention to underlying assumptions. Milojevic [20, p. 631] writes that there is 'hidden bias, like sexism in titles; use of the pronoun 'he' and noun 'man' when discussing 'universal' issues', but also that there is a 'lack of topics of concern to women' and that assumptions held about the future represent 'the typical Western and male way of looking at the world around us'. However, Milojevic [21] argues not only that futurists need to acknowledge gendered ways of selecting issues and theories in futures studies, but also that feminists would benefit from futures tools and methods in articulating feminist projects for the future.

There is also criticism of futures studies as being 'colonised by Western technologybased visions' [28, p. 561], which means that modern futures studies predominantly focus on progress through science and technology, but also war and the possibilities of warfare [21, 28, 29]. Lal [30] questions the use of Western categories such as progress in developing countries like India and even writes that Western feminism can be a form of cultural imperialism. The focus on progress is also criticised for failing to deliver happiness [31, p. 303]. Bussey [31, pp. 303-304] claims that many question the assumption that change in material terms equates to progress, including feminists who empower postmodern discourse with value-focused analyses of power.

While futures studies are criticised for being male-dominated and male-biased, Sargent [23] also highlights the lack of gender perspective and women writers within science fiction. Although this genre reflects attitudes of today, it could help us to change gender roles by providing alternative images of the future. However, Sargent [23, p. 433] writes in 1975 that much 'science fiction written in the past has incorporated conservative and even reactionary attitudes'. Sargent [23, p. 440] is also critical of science fiction writing for not being seriously concerned with the future and wants science fiction to be about ideas and 'show us a world which does not exist, has not existed, but could come into being'. 
Similarly, Hurley in 2008 criticises Hollywood films for having 'too much say in what our collective Earth futures will look like' and calls for other images of the future that can form resistance to the hegemonic images [32, p. 365]. Likewise, Milojevic and Inayatullah [33] challenge the hegemony of Western science fiction, as although it claims universality, it is based on ideas of the future as forward time with technological progress, not cyclical or spiral as in more spiritual non-Western science fiction. Similarly, Sardar [34] writes that cyberspace is being colonised by colonial prejudices. Leach [35, p. 1033] analyses the film Men in Black and writes that the true horror of scenes about the subjugation of women is the humour they invoke.

\subsection{THEME 2: NEW METHODS}

Papers in this meta-study see futures studies as male-dominated and biased and suggest that new issues, methods and perspectives are needed, as are alternative images of the future.

\subsubsection{Issues to include}

One way of solving the male bias in futures studies is to include issues central to feminists, exemplified by Milojevic [21, p. 330] as reproductive rights, violence, maternity leave, equal pay, sexual harassment, street harassment, discrimination and rape. However, feminising futures studies is "ultimately not about devising a 'laundry list' of 'women's issues" [21, p. 343], but about using inclusive decision-making processes that would enhance our (human) ability to get our priorities right and increase our chances for the most favourable outcomes' [21, p. 343]. Jarva [25, p. 1176] calls for the inclusion of 'the worldviews of the female half of humankind' and Milojevic highlights women's/feminist ways of knowing and experiencing time [21]. Scarce [36, p. 705] writes that research is needed into 'relevant topics for women's futures' and Keller [37, pp. 431-432] wants more research to determine special abilities and needs of women. Gaede [38, p. 374] suggests that the central focus of futures studies should be '[g]irls' and boys' foundational needs, humane potential and soul-centred aspirations', that 'inner dynamics of biology and psychology are valued as equally relevant as economy, technology and political-social factors' and that '[p]ersonal transformative methodologies in regard to awareness of values and expansion of consciousness are included' to balance masculine value priorities.

\subsubsection{Decolonising the future: Critical approaches, inclusion and participation}

The criticisms of futures studies reveal a lack of critical and discursive perspectives, which means that underlying assumptions and discourses are not acknowledged and futures studies are putatively objective. Only when understanding values, beliefs and discourses that form the present can we gain the insight to envision or re-vision alternative futures [28, pp. 564-566]. Both Kelly [28] and Hurley [32] use Causal Layered Analysis (CLA) as a way of critically analysing images of the future. 
Hurley uses ecofeminist theory as a basis for analysing images of the future and illuminating alternative pathways towards the future [32, p. 347]. It can be used to assess current systems and provide visions for a better future 'based on goals of ecological health, peace, and social justice' [32, p. 347]. Similarly, Jarva [24, p. 910] argues that in order to develop less gendered approaches to futures research, problems and futures, views originating in the domestic (hestian) sphere have to be studied in that sphere, not outside it, e.g. in 'welfare theory based on male-biased science'. This means that futures research needs to be constructed in a way that is useful in the hestian sphere, but also to gain support in the public (hermean) sphere. This relates to Clarke's [29, p. 606] statement about the best nuclear horror stories being the work of women, who set their stories in the home, the family and close human relationships.

Bussey [31, p. 303] argues that futures studies methods and practices must incorporate 'a sense of mystery founded on a critically spiritual sensibility' in order to be relevant. This is not a feminist text as such, but it mentions feminism as one field that has questioned the accepted meaning of progress. Similarly, Stevenson [40] believes that many methods associated with futures studies do not make us think outside the box, but that feminists sometimes succeed in constructing radically different images of the future.

Eisler [in 19, p. 400] states that 'women's voices, needs, experiences, and aspirations' must be included and Jarva [41, p. 244] calls for the inclusion of 'other' voices which can be seen as counter-cultures to 'the dominant authoritarian and patriarchal monetary economy'. Hurley [32, p. 365] believes that this would require us to 'establish processes to engage with, and listen to, those who are presently on the periphery of power'.

Bruce and Adam [39] call for a gender perspective and the inclusion of women in analysing the impacts software systems such as expert systems. Participation is suggested as a tool for including more voices into futures studies. Mettler and Baumgartner's [42] describe a participatory process where gender is one of many aspects considered in future scenarios, while Montgomery [43] tries to create feminist futures in a workshop setting. She concludes that ' $[\mathrm{g}] \mathrm{g}$ ender equality needs to play a standard part as criteria in evaluating the outcome of all Futures Studies activity' and that one way could be to compare 'the scenario plots to feminist philosophies'.

\subsubsection{The need for alternative futures}

Many writers suggest that feminist descriptions of the future are needed. Scarce [36, p. 705] calls for the 'development of alternative futures for women in all cultures', Bhavnani and Foran [44] and Bussey [31, pp. 310-311] argue for more positive (not dystopian) images of the future, Hurley [32] and Stevenson [40] call for other visions of the future than the hegemonic images and McHale and Choong [45] argue the need for images and metaphors that do not build on the 'image of man' (Economic Man)). Similarly, Masini [11, pp. 1159-1162] underlines the importance of not only foreseeing trends, but also choosing where one wants to go. Sargent [23] proposes that science fiction could provide alternative images of the future and Jarva [41, p. 244] writes that 
'[w]e need to be inventive, to think afresh, and come up with new and bold visions of the future'. Thus, futurists should not only engage in possibles and probables, but also in desirables. But desirable on what basis? Masini [11, p. 1159] writes that futures studies have 'become increasingly linked to philosophic choices, to choices of principle, and to choices of how one is to regard reality, man and society' but that 'this development is not strong enough'.

While some authors focus desirable futures, others focus the steps towards realising those images. Chakravorty [46, p. 939] criticises Joshi [47] for not describing the steps needed for actualising the utopia described. Salleh [48] is critical of post-modern feminism for just deconstructing and not facilitating political action through more positive images of the future. Chakravorty [46, p. 941] states that it is not enough to relive the past, we have to cope with today's problems. Masini [49, p. 249] is even more concrete and uses the term 'vision' when referring to a project for the future, not only an image of the future. According to her, visions consider 'what is possible in the present, in terms of human resources and willingness to change and hence is not detached from reality'. Milojevic [20, p. 632] instead writes that we should continue to be critical about our societies and even though we need to build the future 'our buildings (utopias and visions) should be made from modelling clay, thus not allowing us to stick to them too rigidly'.

\subsection{THEME 3: TOWARDS WOMEN-FRIENDLY / FEMINIST VISIONS}

The idea of futures studies is that the future is not a disconnected end-state, but rooted in both the past and the present [7,8]. Therefore, it is common to look backwards to find trends that might continue in the future. It can be a way of predicting the future in order to be able to plan and adapt to expected situations [10, p. 726]. Predictions can also be used as eye-openers if the probable future is not seen as a preferable future. Some papers related to probable futures are described below, followed by papers relating to possible and preferable futures.

\subsubsection{Looking back and forth}

Probable futures are influenced by assumptions. Page [50, p. 192] underlines that assumptions on e.g. when women get married and have children affect population forecasts. Montgomery [43, p. 378] writes that the concept of family is often understood as eminent, although it includes large uncertainties like legislation aimed at reproductive rights, marriage and children. The linguistic turn underlines that history can be written in many different ways and from different perspectives [51].

Especially early papers related to probable futures found in this meta-analysis look at trends concerning gender roles and claim that things will be all right if we just wait. One example is Cordell et al. [52, p. 367], who identify population, food, education and 
development as the world trends of most concern to women. When looking forward they see trends such as divorce becoming socially and culturally acceptable, '[g]reater acceptance of the working wife and mother', evidence that children may benefit from other than solely the mother taking care of them, female contraception and greater acceptance of unmarried women etc. [52, p. 378]. So, although they highlight problems, they indicate that gender equality will just happen. Similarly, Cleveland [53, p. 36] traces a pattern in women's struggle for fairness in the US and Western Europe 'that, with cultural differences, may play itself out in many other more-or-less democratic societies'. However, Montgomery [43, p. 378] is critical of the expectation that gender equality will gradually materialize if we just wait since this ignores any unexpected events that might hinder or reverse the idea of women's rights and 'maintains that male gender roles will change little'.

Gundelach [54, p. 303] states that it has become more common for women in Europe to have paid jobs, families have become smaller and more fragile, there has been an increase in individualisation and a more fragmented value system. This has influenced the authority structure in families, meaning that more anti-authoritarian values have gained in importance. However, values concerning the family do not lead to family crisis [54, p. 313]. Instead, the family is seen as an important social institution. Goldscheider [55] also focuses the increased gender equality in the public sphere, but concludes that there has been less progress toward gender equality in the private sphere of the family. Increases in divorces are said to have undermined fathers' relationship to their children. These papers are not necessarily feminist, an that is not Smith and Debenham's [56, p. 33] paper either, but it present a computer decision model providing 'easy assistance in making more comprehensive and rational decisions' for e.g. greater numbers of successful marriages and happier families.

Other papers examine trends concerning gender roles and conclude that things are not changing fast enough. Thus, they use probable futures as alarm clocks. Senker [57, p. 362] writes that progress in reducing discrimination against women and ethnic minorities has been slow and that extensive changes in attitudes and policies are needed to secure faster progress. Similarly, Szalai [58] writes that women and men need to change attitudes along with educational and economic improvements in order to accelerate the movement towards symmetrical duties in the family. Lubis [59] looks at gendered roles in his family and how he has changed his views on women, while Rasmussen and Håpnes [60] study the representation of women in higher education in computer science (8-10\% at the Norwegian Institute of Technology in 1991). Women are both wanted and needed, but men continue to dominate 'because the dominant groups among the professors and the students share certain values with the hackers' (a subgroup among male students) [60, p. 1117]. Schneider's [61] paper looks at AIDS and writes that it will continue to affect women for the foreseeable future.

Schumann [62] focuses on women and their possibilities in the labour force in the early 1980s, and warns that advanced computer and information technologies can increase unemployment rates, alienate employees from their work and reinforce traditional roles for women, but also discusses opportunities for combining raising children and other 
duties at home with computerised jobs from home. Reporting on the 'Women and cyberculture workshop' organised by the Society for International Development and UNESCO in 1997, Harcourt [63] also considers technical development but indicates that the internet can open new spaces for women by allowing them to communicate with people all over the world. However, that paper also recognises that although the internet provides many opportunities, it is still embedded in old structures of power, access, knowledge, etc.

\subsubsection{Possible (feminist) futures}

While the futures described above are probable futures, there are also writers presenting possible futures. Montgomery [43, p. 377] organised a 'US families 2025 workshop', which resulted in four scenarios. Montgomery [43, p. 381] describes three of the scenarios as exemplifying harsh extremes since they offer little hope of female empowerment. The fourth scenario may instead 'be seen as a baseline future where business as usual means that future families will be run with entrepreneurial instincts and capitalistic goals, echoing its patriarchal underpinnings' [43, p. 381]. Montgomery also postulates short responses to the scenarios from liberal, utopian, Marxist, postmodern and radical feminism perspectives. None of the alternative futures appeals to any of these feminist strands and Montgomery [43, p. 385] concludes that it is difficult to envision a preferable scenario for the future of US families, but the undesired is clear.

Cerroni-Long [64] writes that new conception opportunities might soon make sexual intercourse unnecessary, which could mean men and women becoming either more or less uniform. So, the future is divergent or convergent when it comes to dimorphism, which means that 'gender characteristics become increasingly polarized and sexuality intensifies in gender-specific ways, possibly leading to exclusive homophilia' or 'gender characteristics fuse into androgyny, and sexuality becomes diffuse and nonspecific, breaking the link between dimorphism and reproduction' [64, p. 789]. Thus she sees either an androgynous or polarised future in terms of gender characteristics.

Mettler and Baumgartner's [42] paper present three scenarios developed in participatory processes designed to 'improve the shaping of technological developments' [42, $\mathrm{p}$. 535]. Around 90 citizens took part in creating scenarios with some gendered differences. In one scenario sexual stereotypes remained unchanged, one was an androgynous future and in the third women adopted male characteristics [42, p. 547].

Another writer presenting possible futures is Scarce [36], who criticises Keeton and Baskin's [65] book 'Women of Tomorrow' for being just one single future for women. As an alternative, he outlines two visions of the future for women in US in 2010: Scenario 1 is 'decline and stagnation' where there is a long-running Arab oil embargo and the US is in a depression. Agriculture is poor due to climate change, power is centralised and women have lost some rights previously won. Families are disintegrating, less than one-third of women have full-time jobs outside the home, pregnant women are not guaranteed their jobs after the birth, sexual harassment is 
commonplace, healthcare is rationed in most areas, etc. [36, pp. 703-704] In Scenario 2, 'sustainable society', the US is undergoing a slow grassroots political and economic revolution and higher value is given to natural environments. Energy prices are high but many choose simple lifestyles. Society is decentralised, women have legal equality with men and the concept of family has been redefined, although many families are still comprise parents (one or two sexes) with children, but households often also contain friends [36, pp. 704-705].

Two possible visions for future education are presented by Milojevic [66]. One is an inclusive, woman-friendly university and the other a women's university in which women's experience is the norm.

\subsubsection{Preferable feminist futures?}

Ihsan [67] states that visions and dreams can help us in searching for a better tomorrow. Below are some storylines from the feminist futures in the papers included in this metastudy. They are varied and it can be discussed whether they are preferable, but they are all descriptions of alternative societies.

Milojevic [in 19, p. 406] states that feminist futures would 'include a shift from death, power, competition and hierarchy-based glorification to a vision where life, love, caring and equality are more valued' and 'while hegemonic futures visions claim to be about 'the real', feminist alternatives are unashamedly utopian'. Similarly, Milojevic et al. [68] argue that in spite of the diversity of feminist movements, a common core for future feminist is 'the awareness that gender issues are important for the future, or at least, that they could be'. However, they also note different opinions on whether the preferred futures is '(1) androgynous, (2) polarised into two separate but equal (male and female) sexes, or (3) composed of the multiplicity of diverse genders' [68, p. 316]; what is clear is that the ranking of one sex/gender over the other has vanished, as has any ranking of some humans over others and humans over cyborgs, other species, and nature in general'.

Sargent's [69] story is the most detailed in this meta-study. It is perhaps not a preferable future, but a science fiction story that can be seen as a criticism of society's gendered roles as it describes an androgynous person from a village where people can choose their bodily appearance.

Miles [70, p. 57] states that a future of vastly more sexual equality 'is hard to imagine', but what is certain is 'that such a future is bound to involve far more than the insertion of women in equal proportions into sites of social privilege'. Furthermore, it will not be 'feminine', but a synthesis of all human potential. Miles [70], like Sargent [69], is perhaps allowing for a multiplicity of different genders. Milojevic [20, pp. 632-633] does too in some ways, but also underlines that in her preferred future women and men are equal partners. However, people are primarily seen as individuals and not as belonging to a certain gender, age-group, body shape, race, class, nation or religion. 
Basic human rights are increasingly met, the environment is clean and there is a sense of a one world community.

Boulding [in 19, p. 394] imagines a shift "to a smaller scale of organization for many aspects of daily life" together with "a more intensive utilization of the human resources of both sexes and all ages and ethnic and racial backgrounds in local communities". This would mean that more societal groups would be engaged in the shaping of a new society.

Fredriksson [71] writes about sex roles and the Swedish view that the role of women and men in society should be equal, meaning that men have to change. Eisler [75] and Loye [76] instead present a polarised vision where the complementary roles of women and men are highlighted. Jahoda [78, p. 415] sees problems with the nuclear family and has two solutions: either divide responsibilities between more people through building a community where 'accommodation is available for ten nuclear families with an eleventh facility for communal purposes: not only washing machines but playrooms for children and adults, the possibility for some communal meals, for living quarters for a professional housekeeper and central shopper, the use of these facilities being not obligatory but open to choice.' The other solution is a radical transformation of how people view love, especially in Western societies. Instead of a nuclear family, Jahoda [78, p. 417] imagines 'a three-generation family, related not by blood, but by the bonds of prolonged sexual and personal experiences, consisting either of two men and one women, or of two women and one man'.

Henderson [72] considers the fact that technical solutions to reproduction open up new ways to examine and experience love and nurture of children and suggests that we should see love as abundant and natural instead of a scarce resource. Thus, love should not only be sexually focused.

Quite a few papers study women in the global South. Meier [73] and Ihsan [67] describe futures where societies are not radically transformed, but more linked to today's institutional structures. They see empowerment of women as important features of feminist futures in the context of Africa and Pakistan. Meier [73] points out that Africa faces many barriers to development (like food supply, population growth, city expansion and political stability) and that women's NGOs can be part of a solution through e.g. expediting entrepreneurship and micro-loans and providing education for girls. Ihsan [67] presents a personal vision of democracy in Pakistan where women can participate and influence.

A socialist vision for Tanzania is proposed by Mbilinyi [74, p. 411], who writes that people would be placed first here, not profit. It would include daycare centres with full medical service, semi-processing and preparation of food to ease women's duties in the home and encourage men to take part in cooking, and a nearby supply of water.

Joshi [47] suggests that women in Asia should begin to weave at home as a way to take back the means of production from large companies. Chakravorty [46, p. 941] criticises this future and writes that '[p]rojecting into the future does not mean going back to the 
past' but a future 'where invisible women are rendered visible, where silent voices are made audible, where gendered power formations can be confronted without any doubts and fears.' This means that values and attitudes must change for women as well as men in a truly egalitarian social structure which is not divided into hierarchies of class, race, religion or gender' and there are no 'class or gendered categories'. Thus, it is a future of multiple genders.

Pym [77, p. 234] argues for a free economy less based on money than the institutional economy and claims that this 'offers greater opportunity to women, those with manual skills, and the permanent resident' and is a way of changing gender roles since ' $[\mathrm{t}] \mathrm{he}$ slavery experienced by many housewives today is not a condition of life in the domestic economy but a consequence of universal employment'.

\subsection{THEME 4: WOMEN AS DRIVERS FOR CHANGE}

Many papers cite women as bearers or drivers for change. Masini has contributed significantly in 'feminising' futures studies and in empowering women to engage in their own future $[25,79,80,81,82]$. She sees women as 'the silent builders of one or many alternative societies' [49, p. 255], outside the present social structures and therefore with 'capacities, yet untapped, which are more congenial to the non-material society, which is emerging and is not based exclusively on industrial development and economics'. Masini [49] wants to upgrade these female qualities into futures studies and argues that women greatly influence children and the young, so to look into the future we should look at women's lives [83]. The idea is that women were marginalised by industrial society, which made them develop their own values and priorities [84].

Hans [85, p. 762] believes that 'women, because of the gendered division of work, have maintained their links to nature which man has not'. Therefore, Hans writes, women are particularly good in providing an alternative paradigm to development and water management in developing countries. This thinking is however highly contested within feminism. Similarly, Huston [86, p. 39] considers crises such as pollution, ecosystem collapse and poverty and argues that '[a]s always in periods of profound disruption, it is women who must show the way'. Huston [86, p. 38] suggests that despite women's diverse experiences, 'there is a common agenda for change and a clear need for women to form a partnership for survival'. Platt also sees women as 'less blinded by the past' [87, p. 425], and areas of special concern to women should be identified where new analyses and reforms are needed to break the male dominance [87, p. 420].

Women tend to emphasise quality of life instead of economic priorities. Masini [11, p. 1163] claims that their lived alternatives may be the solution to the environmental catastrophes we are facing today. Similarly, Milojevic [21, p. 329] underlines that many women's movements work towards building a different future.

Women in developing countries are especially emphasised as drivers of change. Mbilinyi [74, p. 400] writes that since '[i]dle speculation about 'the future' is a luxury 
that women of Africa cannot afford', they are instead engaged in contemporary (paper written in 1975) struggles. However, Mbilinyi [74, p. 400] also states that 'it is difficult to mobilise ourselves without some picture of what the future could be like'.

Joshi [47] takes a socialist starting point and suggests that Asian women take a key role in a social revolution and economic change through producing cloth in villages and city slums. This would be a step in reaching a vision of localised production instead of mass production for global markets. Kapoor [88] underlines the Self-Employment Women's Association (SEWA), a trade union of nearly 700000 women in the informal sector in India, as a good example showing the way forward.

Bhavani and Foran [44, p. 320] believe that development theory and practice should envision a democratic and environmentally sustainable future where non-elites are empowered. They argue 'that women in the Third World meet these challenges and confront them actively, often in remarkably creative and effective ways' [44, p. 325]. Premchander [89] discusses women's role in alleviating poverty through enterprise, NGOs and local micro-financing institutes (MFIs) in India. Meier cites women's NGOs in Africa as part of a solution to many barriers to development [73, pp. 350-351].

Eisler and Loye [90, p. 554] are not as straight-forward in their report from 'UN End of the Decade For Women Conference, Nairobi 1985', but conclude 'that the transformation of values, from 'hard' to 'soft', that futurists have written about $[\ldots]$ is integrally connected with the move from male dominance in our global social system to societies in which women and anything labelled feminine, such as non-violence, are in actual practice no longer sub-dominant'. Eisler [91, p. 13] suggests women as managers of the future since feminine (soft) ways of managing are becoming more popular. These papers can be contrasted with e.g. Ahmad [92], who writes about development in Bangladesh and women's role without highlighting women's capabilities, but merely describing them as victims.

Two writers also write about men and change. Miles [70, p. 56] claims that men must be prepared to confront each other and challenge sexism, support each other in changing male roles and support women's movements. Coote [93, p. 544] is especially interested 'that men should take responsibility, both as individuals and collectively, for their violence to women and girls', which would require a change in men's image of their lives and responsibilities.

\section{Analysis and discussion}

The gender/feminist criticism of futures studies mainly relates to these being maledominated and male-biased, i.e. a future already colonised by men. The criticism is recurrent and while the first special issue on gender in Futures was positive (Let's start working with gender and futures studies!) [94], the 1989 special issue focused on the possibilities to question values and norms in a time of turbulence and rapid change [95]. 
The last special issue concluded that little has happened in terms of gender equality over the years [68].

When synthesising the insights from all 78 papers focusing on futures studies and feminism, gender or women, four conclusions linked to the research questions are especially striking:

1. Women and non-Westerners are generally excluded from professional futures studies activities and so are feminist issues or issues of particular relevance for women.

2. Futures studies usually make no attempts to reveal underlying assumptions, i.e. often lack a critical and reflexive perspective, which is needed in order to add a critical feminist perspective and envision feminist futures.

3. Feminist futures are needed as a contrast to hegemonic male and Western technology-orientated futures. Feminist futures are diverse, but focus on the well-being of all humans.

4. Futures studies often view women as victims, rather than as drivers for change, which means that their alternative futures are often ignored.

Most people would probably endorse the inclusion of women and other excluded voices in professional futures studies activities, but as long as this vision is not elucidated it is unclear what it mean. It could mean a future where there are no formal obstacles for women and other hitherto excluded groups studying and taking part in professional futures studies activities. This could be denoted a future of equality as sameness [96, $\mathrm{p}$. 23], or an androgynous future [68, p. 316]. Thus, the idea is that when any formal obstacles are set aside, women should become part of the futures studies society. However, in many countries there are no formal obstacles to women taking part in higher education or working as researchers, so a future of equal participation perhaps demands that patriarchal norms and structures are questioned in a radical feminist way. This means reducing informal obstacles. In this future, today's valuation of what is seen as 'male' and 'female' ways of being and doing would change and positive aspects of being a woman would be discovered [3, p. 48]. For example, research grants and futures studies professorships could be allocated specifically to women and other groups excluded so far. This could be denoted vision of difference or reversal [96, p. 23].

This meta-study shows that feminising futures studies can also be seen as adding a critical approach and using inclusive processes. So, future equal participation of all societal groups in professional futures studies activities might demand that the gendered world itself is questioned, and not only the exclusion of women or the male norm. It would mean striving for greater transformations. This transformative feminist future would mean a future of plurality, where gender can be done in many ways (not just two) and with no gender or social group being valued more than any other. These groups would take part in professional futures studies activities, but there would also be a reformation of futures studies so that research is performed from a critical and reflexive perspective. This would be a way of questioning universal ways of tackling problems in 
futures studies and its alleged cultural imperialism. Thus, underlying assumptions would be revealed instead of seeing chosen topics and methods as putative objective. Political categories, gendered roles and concepts such as family, education and work would be deconstructed and reconstructed. This would challenge the focus on progress as change in material terms. However, the emphasis on difference and deconstruction would also have its downside, since it would be difficult to speak in general terms.

From a feminist standpoint images of futures are troublesome because of their universalistic notions of what is good. Second wave feminist theory has been criticised for being white and Western and not acknowledging black women, the Third World, gay and lesbian people etc. It is now inspired by the post-modern criticism of universalism, which means that it is becoming more difficult to call for the feminist future [see e.g. 97, 98]. However, many feminist futurists believe we have a responsibility for future generations to do just that. Similarly, in the field of planning Sandercock [99] sees a challenge in how to build cities where 'we' (meaning all of us) feel at home, Fainstein [100] calls for the just city and Young [101] develops an ideal of city life as a vision that affirms group difference. Feminist futures could give input to and change the planning discourse from universalistic to planning for multiple publics.

One result of this meta-study is the strong call for alternative feminist futures as a contrast to hegemonic Western, white and male futures. This is also a call for feminist futures to be a call for a diversity of futures, since the feminist movement is so diverse. This diversity is evident in the papers studied and it is impossible to identify one feminist meta-theory, method or image of the future.

This meta-study discusses the feminist criticism of mainstream futures studies for focusing probable futures, but also shows that these can be useful as alarm clocks. Note that the criticism about futures studies focusing on probable futures is somewhat misdirected, since normative futures studies and backcasting are common approaches in the field. However, normative images of the future and backcasting studies are usually done without a gender perspective. The feminist criticism also pinpoints what Andersson [102, p. 3] denotes science and imagination as two central and rivalling futures strategies: Is the future 'an objective, pre-existing sphere of which we may be capable at least of fragmentary observations that can be empirically or deductively transformed into some kind of knowledge about the future' or a human imagining? Creating 'better' futures is thus not unique for feminists writing in the field of futures studies. Bell [7, p. 73] actually presents futurists as humanists devoted to creating better futures: ' $[t]$ he most general purpose of futures studies is to maintain or improve the freedom and welfare of humankind', while Andersson [103, p. 288] notes that when futures studies developed in Sweden they were seen as having particular responsibility for society's weakest groups.

The fields of futures studies and feminism still have much to learn from each other. Futures studies need to be better at including women, and non-Westerners in general, in their professional activities. They need to include feminist issues and allow for radically different ways of describing gender relations in the future, and become better at 
revealing underlying assumptions and using critical and reflexive perspectives. Lastly, futures studies need to include feminist/gender perspectives when elaborating images of the future. It seems odd to imagine great changes in technological developments, the environment, education, peace, economics, governance, and all professions without any changes in gendered roles. Feminist/gender studies can benefit from the theories and methods available in the futures studies field to develop feminist images of the future. These should not be seen as a common united goal, but as something to base political discussions on diverse futures.

\section{Acknowledgments}

Thanks for comments from seminar participants, and in particular to Göran Cars, Johan Hedrén, Mattias Höjer and Åsa Svenfelt whom have all read and provided valuable comments. Thanks also to two anonymous reviewers for thoughtful comments.

My gratitude also goes to Mary McAfee, who language-checked this paper.

VINNOVA, the Swedish Government Agency for Innovation Systems, is gratefully acknowledged for providing the funding for the research.

\section{References}

[1] B.L. Paterson, et al., Meta-study of qualitative health research: a practical guide to meta-analysis and meta-synthesis. 2001, Thousand Oaks, Calif.: Sage.

[2] R. Tong, J.S. Neil, and B.B. Paul, Feminist Theory, in International Encyclopedia of the Social \& Behavioral Sciences. 2001, Pergamon: Oxford. p. 5484-5491.

[3] L. Gemzöe, Feminism 2002, Stockholm: Bilda. 192.

[4] F. Haug, On the necessity of conceiving the utopian in a feminist fashion The Socialist register, 2000: p. 53-66.

[5] Vetenskapsrådet, Genusforskning i korta drag. 2005, Vetenskapsrådets kommitté för genusforskning: Stockholm.

[6] C. West and D.H. Zimmerman, Doing Gender. Gender and Society, 1987. 1(2): p. 125-151.

[7] W. Bell, Foundations of futures studies: human science for a new era. vol. 1, History, purposes, and knowledge 2003, New Brunswick, NJ Transaction Publishers. 
[8] R. Koselleck, Erfarenhet, tid och historia: om historiska tiders semantik 1979/2004, Göteborg: Daidalos.

[9] T. Fuller and K. Loogma, Constructing futures: A social constructionist perspective on foresight methodology. Futures, 2009. 41(2): p. 71-79.

[10] L. Börjeson, et al., Scenario types and techniques: Towards a user's guide. Futures, 2006. 38(7): p. 723-739.

[11] E. Masini, Rethinking futures studies. Futures, 2006. 38(10): p. 1158-1168.

[12] Elsevier. Futures: Product Description. [cited 2010 February 10]; Available from:

http://www.elsevier.com/wps/find/journaldescription.cws_home/30422/descri ption\#description.

[13] ISI Web of Knowlege. JCR Social Science Edition. 2008 [cited 2010-02-08]; Available from: www.isiknowledge.com.

[14] Elsevier. Technological Forecasting and Social Change. 2010 [cited 2010 2010-02-08].

[15] L. John Wiley \& Sons. Product Information. [cited 2010 February 10]; Available from:

http://www3.interscience.wiley.com/journal/2966/home/ProductInformation.ht $\mathrm{ml}$.

[16] Elsevier. Futures: Guide for authors. 2008 [cited 2008 September 10];

Available from:

http://www.elsevier.com/wps/find/journaldescription.cws_home/30422/authori nstructions.

[17] S.S. Fainstein and L.J. Servon, Introduction: The Intersection of Gender and Planning, in Gender and Planning: A Reader, S.S. Fainstein and L.J. Servon, Editors. 2005, Rutgers University Press: New Brunswick.

[18] K. Hurley, Food in the future: Does futures studies have a role to play? Futures, 2008. 40(7): p. 698-701.

[19] K. Hurley, et al., Futures studies and feminism. Futures, 2008. 40(4): p. 388407.

[20] I. Milojevic, History, feminism and futures. Futures, 1996. 28(6-7): p. 629633.

[21] I. Milojevic, Timing feminism, feminising time. Futures, 2008. 40(4): p. 329345.

[22] Z. Sardar, Colonizing the future: the [']other' dimension of futures studies. Futures, 1993. 25(2): p. 179-187. 
[23] P. Sargent, Women in science fiction. Futures, 1975. 7(5): p. 433-441.

[24] V. Jarva, Gendered society, gendered futures research. Futures, 1998. 30(9): p. 901-911.

[25] V. Jarva, Bridges over troubled waters: Observations on the futures work of Eleonora Masini. Futures, 2006. 38(10): p. 1169-1178.

[26] D. Hicks, A lesson for the future : Young people's hopes and fears for tomorrow. Futures, 1996. 28(1): p. 1-13.

[27] L. Tepperman and J. Curtis, Popular images of the future : Cross-national survey results, 1981 and 1991. Futures, 1995. 27(5): p. 549-570.

[28] P. Kelly, In occupied territory: future.con. Futures, 2002. 34(6): p. 561-570.

[29] I.F. Clarke, 20Th century future-think : From the flame deluge to the bad time. Futures, 1992. 24(6): p. 605-614.

[30] V. Lal, Discipline and authority : Some notes on future histories and epistemologies of India. Futures, 1997. 29(10): p. 985-1000.

[31] M. Bussey, From change to progress: critical spirituality and the futures of futures studies. Futures, 2002. 34(3-4): p. 303-315.

[32] K. Hurley, Is that a future we want?: An ecofeminist exploration of images of the future in contemporary film. Futures, 2008. 40(4): p. 346-359.

[33] I. Milojevic and S. Inayatullah, Futures dreaming outside and on the margins of the western world. Futures, 2003. 35(5): p. 493-507.

[34] Z. Sardar, Coming home : Sex, lies and all the 'l' in India. Futures, 1997. 29(10): p. 891-908.

[35] J. Leach, Here come the men in black: Technology and anxiety in the postmodern age. Futures, 1998. 30(10): p. 1027-1035.

[36] R. Scarce, Women of tomorrow: Issues and alternative futures. Futures, 1987. 19(6): p. 701-706.

[37] G. Keller, Women and the future of education. Futures, 1975. 7(5): p. 428432.

[38] M.G. Gaede, Futures: A question of values-consciousness-choices. Futures, 2008. 40(4): p. 360-376.

[39] M. Bruce and A. Adam, Expert systems and women's lives: A technology assessment. Futures, 1989. 21(5): p. 480-497.

[40] T. Stevenson, Will our futures look different, now? Futures, 2000. 32(1): p. 91-102. 
[41] V. Jarva, Dissenting identities: Karelian strong women's futures voices. Futures, 1999. 31(2): p. 235-244.

[42] P.H. Mettler and T. Baumgartner, Large-scale participatory co-shaping of technological developments: First experiments with PARDIZIPP. Futures, 1998. 30(6): p. 535-554.

[43] A. Montgomery, US Families 2025: In search of future families. Futures, 2008. 40(4): p. 377-387.

[44] K.-K. Bhavnani and J. Foran, Feminist futures: From dystopia to eutopia? Futures, 2008. 40(4): p. 319-328.

[45] M.C. McHale and P. Choong, A measure of humanity. Futures, 1989. 21(1): p. 91-93.

[46] S.B. Chakravorty, Can women change the future? Futures, 1992. 24(9): p. 938-941.

[47] N. Joshi, Women can change the future. Futures, 1992. 24(9): p. 931-937.

[48] A. Salleh, The dystopia of technoscience: An ecofeminist critique of postmodern reason. Futures, 2009. 41(4): p. 201-209.

[49] E.B. Masini, A vision of futures studies. Futures, 2002. 34(3-4): p. 249-259.

[50] W. Page, 11. Population forecasting. Futures, 1973. 5(2): p. 179-194.

[51] A. Dirlik, Whither history? Encounters with historicism, postmodernism, postcolonialism. Futures, 2002. 34(1): p. 75-90.

[52] M. Cordell, J. McHale, and G. Streatfeild, Women and world change. Futures, 1975. 7(5): p. 364-384.

[53] H. Cleveland, Information, fairness and the status of women. Futures, 1989. 21(1): p. 33-37.

[54] P. Gundelach, Recent value changes in Western Europe. Futures, 1992. 24(4): p. 301-319.

[55] F.K. Goldscheider, Men, children and the future of the family in the third millennium. Futures, 2000. 32(6): p. 525-538.

[56] G.W. Smith and J.D. Debenham, Mass producing intelligence for a rational world. Futures, 1983. 15(1): p. 33-46.

[57] P. Senker, Technological change and the future of work: An approach to an analysis. Futures, 1992. 24(4): p. 351-363.

[58] A. Szalai, Women's time : Women in the light of contemporary time-budget research. Futures, 1975. 7(5): p. 385-399.

[59] M. Lubis, In praise of women and sufferings. Futures, 1989. 21(1): p. 66-71. 
[60] B. Rasmussen and T. Håpnes, Excluding women from the technologies of the future? : A case study of the culture of computer science. Futures, 1991. 23(10): p. 1107-1119.

[61] B.E. Schneider, Women and AIDS : An international perspective. Futures, 1989. 21(1): p. 72-90.

[62] G. Schumann, The macro- and microeconomic social impact of advanced computer technology. Futures, 1984. 16(3): p. 260-285.

[63] W. Harcourt, Women and cyberculture: Communication transgressions. Futures, 1998. 30(2-3): p. 249-254.

[64] E.L. Cerroni-Long, Sexual dimorphism: divergent or convergent? Futures, 2000. 32(8): p. 783-791.

[65] K. Keeton and Y. Baskin, Woman of Tomorrow. 1985, New York: St. Martin's.

[66] I. Milojevic, Women's higher education in the 21st century: From 'women friendly' towards women's universities. Futures, 1998. 30(7): p. 693-703.

[67] S. Ihsan, A Pakistani woman's vision. Futures, 1993. 25(3): p. 354-355.

[68] I. Milojevic, K. Hurley, and A. Jenkins, Futures of feminism. Futures, 2008. 40(4): p. 313-318.

[69] P. Sargent, The human shore. Futures, 1989. 21(1): p. 24-32.

[70] I. Miles, Masculinity and its discontents. Futures, 1989. 21(1): p. 47-59.

[71] I. Fredriksson, The future role of women. Futures, 1969. 1(6): p. 532-540.

[72] H. Henderson, Towards holistic human relationships. Futures, 1989. 21(1): p. 6-12.

[73] R.L. Meier, A hopeful path for development in Africa. Futures, 1996. 28(4): p. 345-358.

[74] M. Mbilinyi, Tanzanian women confront the past and the future. Futures, 1975. 7(5): p. 400-413.

[75] R. Eisler, The partnership society: Social vision. Futures, 1989. 21(1): p. 1318.

[76] D. Loye, The partnership society: Personal practice. Futures, 1989. 21(1): p. 19-23.

[77] D. Pym, Towards the dual economy and emancipation from employment. Futures, 1980. 12(3): p. 223-237.

[78] M. Jahoda, Technicalities and fantasy about men and women. Futures, 1975. 7(5): p. 414-419. 
[79] W. Bell, Eleonora Masini on the empowerment of women. Futures, 2006. 38(10): p. 1179-1186.

[80] T. Stevenson, Eleonora Masini: Nurturing visions of the future. Futures, 2006. 38(10): p. 1146-1157.

[81] T. Stevenson, Eleonora Masini: Hope against the tide. Futures, 2006. 38(10): p. 1139-1145.

[82] J.M. Vasquez, The legacy of Eleanora Masini: Reflections from Latin America. Futures, 2006. 38(10): p. 1187-1195.

[83] E.B. Masini, Women and the young in perspective. Futures, 1989. 21(1): p. 60-65.

[84] E.B. Masini, Women as builders of the future. Futures, 1987. 19(4): p. 431436.

[85] A. Hans, Locating women's rights in the Blue Revolution. Futures, 2001. 33(89): p. 753-768.

[86] P. Huston, What is a woman, today? Futures, 1989. 21(1): p. 38-46.

[87] J. Platt, Women's roles and the great world transformation. Futures, 1975. 7(5): p. 420-427.

[88] A. Kapoor, The SEWA way: Shaping another future for informal labour. Futures, 2007. 39(5): p. 554-568.

[89] S. Premchander, NGOs and local MFIs--how to increase poverty reduction through women's small and micro-enterprise. Futures, 2003. 35(4): p. 361-378.

[90] R. Eisler and D. Loye, Will women change the world? Futures, 1985. 17(5): p. 550-555.

[91] R. Eisler, Women, men, and management: Redesigning our future. Futures, 1991. 23(1): p. 3-18.

[92] Q.K. Ahmad, Policies and strategies for sustainable development in Bangladesh. Futures, 1992. 24(9): p. 879-893.

[93] J. Coote, Towards new ways for gender relating down under. Futures, 1996. 28(6-7): p. 543-546.

[94] G. Streatfeild, Women's year and beyond. Futures, 1975. 7(5): p. 362-363.

[95] M. McHale, Introduction : Towards a renewed humanism. Futures, 1989. 21(1): p. 3-5.

[96] M. Verloo and E. Lombardo, Contested Gender Equality and Policy Variety in Europe: Introducing a Critical Frame Analysis Approach, in Multiple 
Meanings of Gender Equality: A Critical Frame Analysis of Gender Policies in Europe, M. Verloo, Editor. 2007, CEU Press: Budapest.

[97] L. Sandercock and A. Forsyth, Feminist Theory and Planning Theory: The Epistemological Linkages. Planning Theory, 1992. 7-8: p. 45-49.

[98] L. Edelman, No future: queer theory and the death drive. 2004, Durham: Duke University Press

[99] L. Sandercock, Cosmopolis II: mongrel cities in the 21st century. 2003, London: Continuum.

[100] S.S. Fainstein, Planning and the Just City, in Searching for the just city: Debates in urban theory and practice, P. Marcuse, et al., Editors. 2009, Routledge: New York.

[101] I.M. Young, Justice and the politics of difference. 1990, Princeton: Princeton Univ. Press

[102] J. Andersson, The Future Landscape, in Working papers. 2008, Institute for Futures Studies: Stockholm. p. 18.

[103] J. Andersson, Choosing Futures: Alva Myrdal and the Construction of Swedish Futures Studies, 1967 - 1972. International Review of Social History, 2006. 51(02): p. 277-295. 